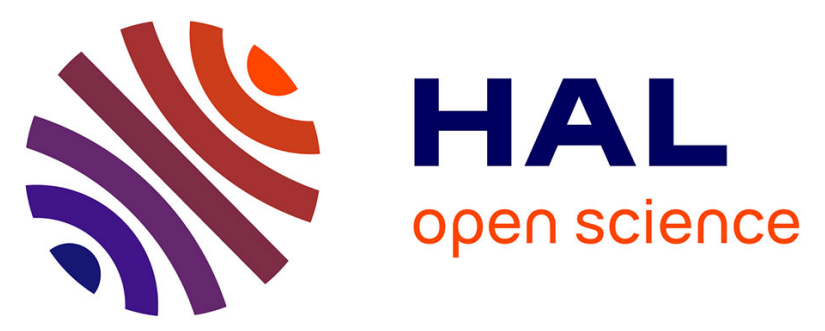

\title{
Immunological environment in colorectal cancer: a computer-aided morphometric study of whole slide digital images derived from tissue microarray
}

Daniel Eyraud, Benjamin Granger, Armelle Bardier, Yann Loncar, Gaëlle Gottrand, Gilles Le Naour, Jean-Michel Siksik, Jean-Christophe Vaillant, David Klatzmann, Louis Puybasset, et al.

\section{To cite this version:}

Daniel Eyraud, Benjamin Granger, Armelle Bardier, Yann Loncar, Gaëlle Gottrand, et al.. Immunological environment in colorectal cancer: a computer-aided morphometric study of whole slide digital images derived from tissue microarray. Pathology, 2018, 50 (6), pp.607 - 612. 10.1016/j.pathol.2018.04.006 . hal-01895443

\section{HAL Id: hal-01895443 \\ https://hal.sorbonne-universite.fr/hal-01895443}

Submitted on 15 Oct 2018

HAL is a multi-disciplinary open access archive for the deposit and dissemination of scientific research documents, whether they are published or not. The documents may come from teaching and research institutions in France or abroad, or from public or private research centers.
L'archive ouverte pluridisciplinaire HAL, est destinée au dépôt et à la diffusion de documents scientifiques de niveau recherche, publiés ou non, émanant des établissements d'enseignement et de recherche français ou étrangers, des laboratoires publics ou privés. 


\title{
Immunological environment in colorectal cancer: a computer-aided morphometric study of whole slide digital images derived from tissue microarray
}

\author{
Daniel Eyraud ${ }^{1,2,3}$, Benjamin Granger ${ }^{4}$, Armelle Bardier ${ }^{2}$, Yann Loncar ${ }^{1}$, \\ GaËlle Gottrand $^{3}$, Gilles Le Naour ${ }^{2}$, Jean-Michel SiksiK ${ }^{5}$, \\ Jean-Christophe Vaillant ${ }^{5}$, David Klatzmann ${ }^{3}$, Louis Puybasset ${ }^{1}$, \\ Frederic Charlotte ${ }^{2}$, Jeremy Augustin ${ }^{2}$ \\ ${ }^{1}$ Département d'Anesthésie-Réanimation, Hôpital Pitié-Salpêtrière, Paris, France; ${ }^{2}$ Service \\ d'Anatomie Pathologique, UIMAP, Hôpital Pitié-Salpêtrière, Paris, France; ${ }^{3}$ Service de \\ Biothérapies, UPMC, CNRS 7211, INSERM 959, Hôpital Pitié-Salpêtrière, Paris, France; \\ ${ }^{4}$ Département de Biostatistiques, de Santé Publique et d'Information Médicale, Hôpital Pitié- \\ Salpêtrière, Paris, France; ${ }^{5}$ Service de Chirurgie Digestive et de Transplantation Hépatique, \\ Hôpital Pitié-Salpêtrière, Paris, France
}

\begin{abstract}
Summary
Cancer research has moved from investigating tumour cells to including analysis of the tumour microenvironment as well. The aim of this study was to assess the cellular infiltrate of colorectal cancer (CRC) using computer-aided analysis of whole slide digital image derived from tissue microarray (TMA). TMA slides from $31 \mathrm{CRC}$ patients were immunostained for forkhead box protein 3 (FOXP3) and immunomodulatory enzyme indoleamine 2,3-dioxygenase (IDO) at four sites: centre $(C)$ and invasive front $(F)$ of the tumour, proximal non-metastatic draining lymph node $(\mathrm{N}-)$, tumour-draining lymph node with metastasis $(\mathrm{N}+)$ and healthy mucosa at $10 \mathrm{~cm}$ from the cancer (M). We analysed the proportion of IDO+ tissue areas in the lamina propria or in the non-epithelial area of the lymph node and in epithelial cells in each site. The normal mucosa of patients operated on for benign disease was also analysed. The proportion (\%) of FOXP3+ tissue area in C, F, N-, N+ and $\mathrm{M}$ were $2.3 \pm 1.8,2.6 \pm 2.9,6.0 \pm 2.9,14.2 \pm 5.8$ and $1.2 \pm 0.8(p<0.001)$. The proportion $(\%)$ of IDO+ tissue area in the lamina propria of $\mathrm{C}, \mathrm{F}, \mathrm{N}-, \mathrm{N}+$ and $\mathrm{M}$ were $1.6 \pm 3.1,1.1 \pm 1.3,3.4 \pm 2.5,9.1 \pm 8.5$ and $6.7 \pm 5.4$ $(p<0.001)$. IDO+ tissue area in the lamina propria was not significantly different between healthy mucosa of patients with cancer than without $(1.8 \pm 3$ vs $1.1 \pm 0.95)$. The proportion of IDO positive tissue area in the epithelium was significantly higher in healthy mucosa of patients with cancer than without $(5.4 \pm 13.8$ vs $2.1 \pm 2.4)$. The FOXP3+ tissue area was increased in healthy mucosa of CRC patients in comparison with healthy mucosa of patients with colorectal resection for disease other than cancer: $1.20 \pm 1.81$ versus $0.81 \pm 0.51(p<0.05)$. The proportion of IDO+ tissue area in lymph node $(\mathrm{N}-)$ was correlated with the proportion of FOXP3+ tissue area in tumour area $(r=0.44, p<0.01)$. TMA technique permits simultaneous analysis of FOXP3+ and IDO+ cells at different sites including tumour, draining non-metastatic lymph node, metastatic lymph node and normal mucosa.
\end{abstract}

Key words: Digital imaging; colorectal cancer; microenvironment; regulatory $\mathrm{T}$ cells; tissue microarray; FOXP3; IDO.

\section{INTRODUCTION}

Colorectal cancer (CRC) is the most common gastrointestinal malignancy and one of the leading causes of cancer-related deaths worldwide. ${ }^{1}$ Factors such as tumour invasion and frequency of lymph node or distant metastases determine the prognosis of the disease. Recently, studies of inflammatory cells in cancer have gained increasing interest, particularly with regard to tumour invasiveness and metastases. The composition of the microenvironment of several tumour types, especially CRC, could serve as prognostic factors, 2,3 although others advocate that the TNM stage should remain the preferred prognostic system. ${ }^{4}$ More research on the inflammatory infiltrate in the tumour and the microenvironment both in the tumour and lymph node could help to improve our understanding of tumour genesis. 5,6 The inflammatory infiltrate consists of different $\mathrm{B}$ and $\mathrm{T}$ lymphocytes, mast cells, macrophages, antigen-presenting cells (APC), fibroblasts, and endothelial cells. Among these cells, regulatory T lymphocytes (Tregs) play a crucial part in the inflammatory response in $\mathrm{CRC}^{7-10}$ and can be detected by immunohistochemistry, using forkhead box protein 3 (FOXP3) as a marker. ${ }^{11}$ Moreover, considerable evidence now supports the concept that cells expressing indoleamine 2,3-dioxygenase (IDO) can suppress T-cell responses and promote tolerance. $^{12}$ In CRC, high expression of IDO by colorectal tumour cells enables certain cancer subsets to avoid immune attack and defeat the invasion of $\mathrm{T}$ cells via local tryptophan (Trp) depletion. $^{13}$

The first aim of our study was to describe precisely the proportion of FOXP3+ and IDO+ cells at the centre of the tumour and invasive front, proximal draining lymph node, and healthy mucosa. Our histopathology department has 
developed a computer-aided analysis of whole slide digital image derived from tissue microarray (TMA). ${ }^{14}$ This new analysis overcomes the considerable challenges of classic methods due to tumour heterogeneity, the extreme difficulty of reproducing semi-quantitative analysis results, and the time-consuming nature of analysing whole-tissue samples. The second aim of this study was to compare IDO+ infiltration in the tissues with plasma IDO concentration, evaluated with serum kynurenine (Kyn) level and the Kyn/Trp ratio.

\section{MATERIALS AND METHODS}

\section{Patients}

This prospective longitudinal observational study was conducted in a single institution, Pitié-Salpétrière Hospital, Paris, France, with approval of the local ethics committee.

Thirty-one patients who were operated on for CRC in our institution between March 2010 and September 2011 were included in the study. Prior to TMA construction, all diagnoses were established according to classical histopathological criteria. Analysis of mismatch repair status by immunohistochemistry was performed as described elsewhere. ${ }^{8}$ A patient was considered MSI+ if there was DNA microsatellite instability (MSI), meaning deficiency in the mismatch repair system, and MSI- if no MSI existed. Tumour micro-invasive status was defined by the presence of vascular emboli, lymphatic invasion, and perineural invasion (collectively referred to as VELIPI); patients were scored from 0 to 3 according to the status of each parameter ( 0 negative, 1 positive). Demographic parameters and the main characteristics of patients' tumours are reported in Table 1 .

\section{Construction of TMA}

For each paraffin-embedded tissue donor block, five tissue cylinders with a diameter of $0.6 \mathrm{~mm}$ were punched from morphologically representative areas

Table 1 Demographic and histological characteristics of the 31 patients with CRC

\begin{tabular}{|c|c|}
\hline Characteristics & No. patients \\
\hline Age, years, mean \pm SD & $63 \pm 12$ \\
\hline Sex ratio $(M / F)$ & $19 / 12$ \\
\hline \multicolumn{2}{|l|}{$\mathrm{T}$ stage } \\
\hline $\mathrm{T} 1$ & 1 \\
\hline $\mathrm{T} 2$ & 2 \\
\hline $\mathrm{T} 3$ & 19 \\
\hline $\mathrm{T} 4$ & 9 \\
\hline \multicolumn{2}{|l|}{$\mathrm{N}$ stage } \\
\hline No & 15 \\
\hline N1 & 8 \\
\hline N2 & 8 \\
\hline \multicolumn{2}{|l|}{$M$ stage } \\
\hline MO & 23 \\
\hline M1 & 8 \\
\hline \multicolumn{2}{|l|}{ MSI status } \\
\hline+ & 3 \\
\hline- & 28 \\
\hline \multicolumn{2}{|l|}{ VELIPI status } \\
\hline 0 & 13 \\
\hline 1 & 8 \\
\hline 2 & 3 \\
\hline 3 & 7 \\
\hline \multicolumn{2}{|l|}{ TNM staging } \\
\hline I & 4 \\
\hline IIA & 12 \\
\hline IIC & 1 \\
\hline IIIB & 3 \\
\hline IIIC & 3 \\
\hline IVA & 4 \\
\hline IVB & 4 \\
\hline
\end{tabular}

TNM staging according the AJCC 8th edition.

MSI, microsatellite instability; VELIPI, venous embolism, lymphatic invasion, perineural invasion. at four sites: centre of the tumour (C), invasive front of the tumour $(\mathrm{F})$, a proximal tumour-draining lymph node without metastasis $(\mathrm{N}-)$, metastatic tumour-draining lymph node $(\mathrm{N}+)$, and healthy mucosa (M) located $10 \mathrm{~cm}$ from the tumour. These cylinders were brought into a recipient paraffin block using a semi-automated tissue arrayer (Alphelys, France). Healthy mucosa of patients operated on for diseases other than cancer was also included in the same TMA to analyse IDO and FOXP3 expression in comparison with that of CRC patients.

\section{Immunohistochemistry}

The immunostaining procedure was performed on formalin fixed, deparaffinised, $4 \mu \mathrm{m}$ thick TMA sections using a biotin-free polymeric visualisation system (Ultravison LP, ref TL-015-HD; Lab Vision, USA). The following primary antibodies were used at the indicated dilutions: mouse monoclonal anti-IDO antibody (dilution 1:100; clone 10.1; Chemicon-Millipore, France); mouse monoclonal anti-human FOXP3 (dilution 1:200; clone 236A/E7; Abcam, UK). Matched isotype control antibody was used to choose the best IDO antibody dilution and minimise staining background. The antigen retrieval reaction was performed in a water bath, using EDTA buffer ( $\mathrm{pH}$ 8.0) for $20 \mathrm{~min}$ at $97^{\circ} \mathrm{C}$. The slides were then incubated with the peroxidase block supplied by the manufacturer of the visualisation system for $10 \mathrm{~min}$. Next, the slides were incubated with the primary antibodies for $60 \mathrm{~min}$ at room temperature. The incubation time was $10 \mathrm{~min}$ for each step of the visualisation system. Chromogen diaminobenzidine supplied by the manufacturer was applied for $5 \mathrm{~min}$, and counterstaining with haematoxylin for $1 \mathrm{~min}$.

\section{Computer-aided morphometric study of whole slide digital images} from TMA

TMA glass slides stained with FOXP3 or IDO were scanned to produce digital slides $(0.25 \mu \mathrm{m} /$ pixel at $40 \times$ magnification $)$ using the Aperio Slide Scanning System (ScanScope CS; Aperio Technologies, USA). The whole slide digital images were viewed on a Barco Coronis fusion 6MP highdefinition screen (Barco NV, Belgium) to determine the detection thresholds, and images were analysed with ICS software (Tribvn SA, France). This software is able to discriminate the immunostained area on the basis of red, green, and blue colour segmentation and to calculate the immunoreactive area. Given that an accurate optical count of immunoreactive cells was not feasible in the presence of very dense infiltrates, we did not attempt to convert area values to number of cells. We manually distinguished two types of IDO positive tissue area: on one hand, dendritic cells located in the lamina propria of normal mucosa or in the stroma of carcinomatous samples (expressed as a fraction of the area occupied by lamina propria or stroma) and, on the other hand, normal or neoplastic epithelial cells (expressed as a fraction of the area occupied by epithelial cells). We determined in $\mathrm{C}, \mathrm{F}$ and $\mathrm{M}$, the proportion of IDO+ area of each type. FOXP3 was expressed as a fraction of the TMA spot area. Concerning the lymph nodes, FOXP3 and IDO were expressed as a fraction of the TMA spot area. Finally, we obtained for each case, the mean of the results calculated for five TMA spots for each site $(\mathrm{C}, \mathrm{F}, \mathrm{N}-, \mathrm{N}+, \mathrm{M})$ for FoxP3+ cells, IDO+ dendritic cells, and IDO+ epithelial (normal or neoplastic) cells, respectively.

\section{Measurements of serum Trp and Kyn}

Blood samples (sheltered from light) were obtained using a standard phlebotomy protocol immediately before each patient was anaesthetised. At the time of blood sampling, the patients had not received any treatment, including surgery, chemotherapy, or radiation therapy. No patients had hepatic or renal insufficiency or neuro-psychiatric disease. The samples were rapidly separated, and serum samples were frozen at $-70{ }^{\circ} \mathrm{C}$ until batch processing. The concentrations of Trp and Kyn were measured simultaneously by highperformance liquid chromatography with fluorescence detection, according to the protocol of Yamada et al. ${ }^{15}$ The IDO activity was determined by dividing the serum concentration of Kyn by that of Trp (Kyn/Trp).

\section{Statistical analysis}

For the between site comparison, within the CRC patient group, we tested the overall effect of the site by a one way analysis of variance (ANOVA) and compared the site two by two with a post-hoc test of Tukey.

For the between group comparison, we used a two sample Wilcoxon test and computed $p$ values adjusted using Bonferroni method. 
For the association between baseline characteristics and different measures of FOXP3, IDO, Kyn and Try, we used one ANOVA with a post-hoc test of Tukey or two sample Wilcoxon test and computed $p$ values using Bonferroni method For the association between paired samples we used Spearman's rho $(r)$ and computed $p$ values adjusted using Bonferroni method.

All tests involved use of R 2.15.2 (R Foundation, Austria).

\section{RESULTS}

Demographic and histological characteristics of patients are summarised in Table 1. According to multivariate analysis, there were no differences in the proportion of tissue areas positive for IDO and FOXP3 in any site according to T, N, M stage or VELIPI status.

\section{Patterns of FOXP3 and IDO expression}

The Foxp3 marker gave a distinct nuclear staining (Fig. 1A,C,E,G). The proportion of tissue area positive for FoxP3 varied for different samples between $1 \%$ and $20 \%$. The majority (97\%) of samples had positive area for FOXP3 of $<10 \%$.

The expression of IDO was detected in the cytoplasm of tumour cells, normal epithelium, and immune cells (Fig. 1B,D,F,H). The proportion of tissue area positive for IDO varied among samples from $0.1 \%$ to $100 \%$ in epithelium and from $0.04 \%$ to $16.8 \%$ in lamina propria. The staining of IDO occurred in both the luminal and basal poles of tumour
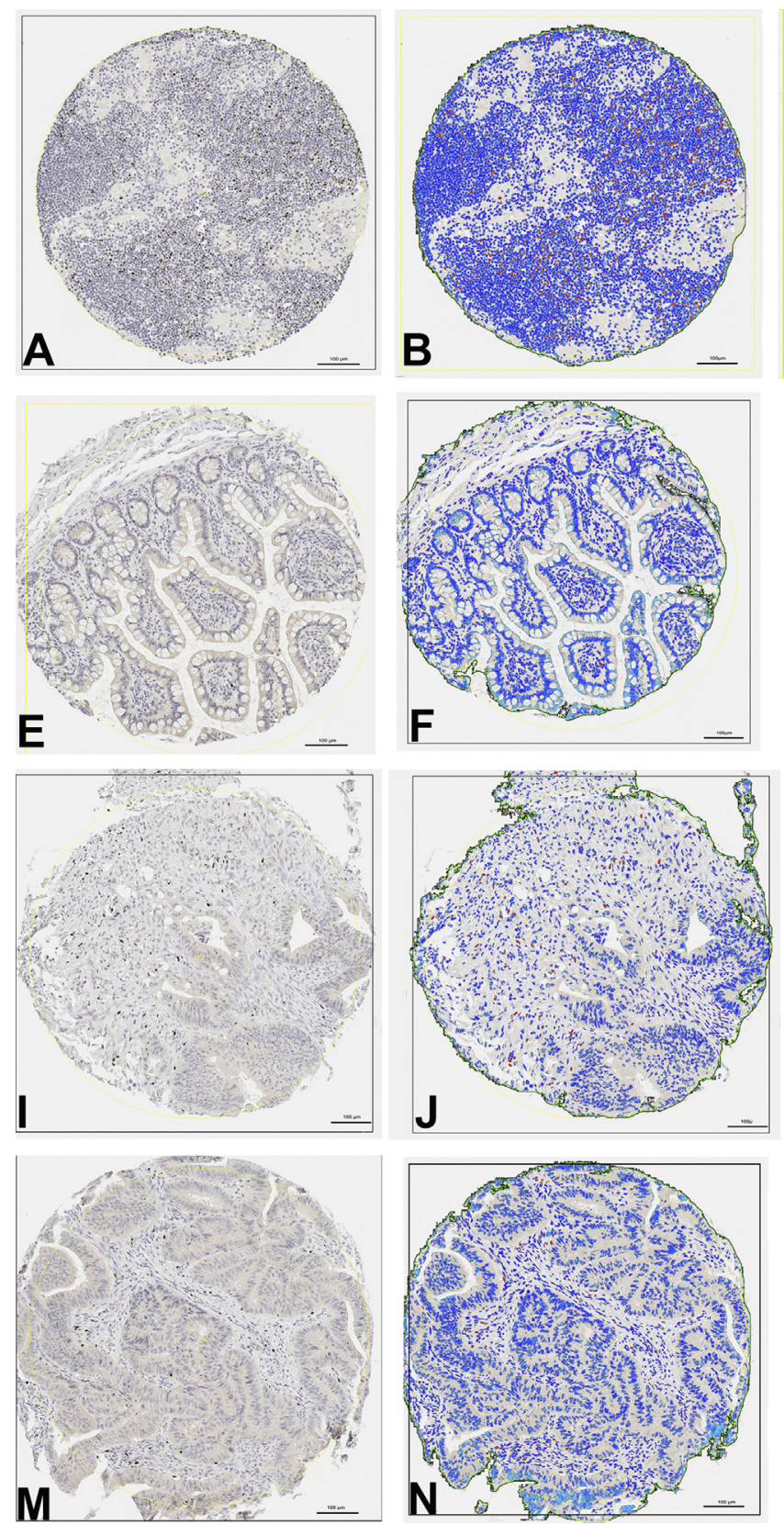
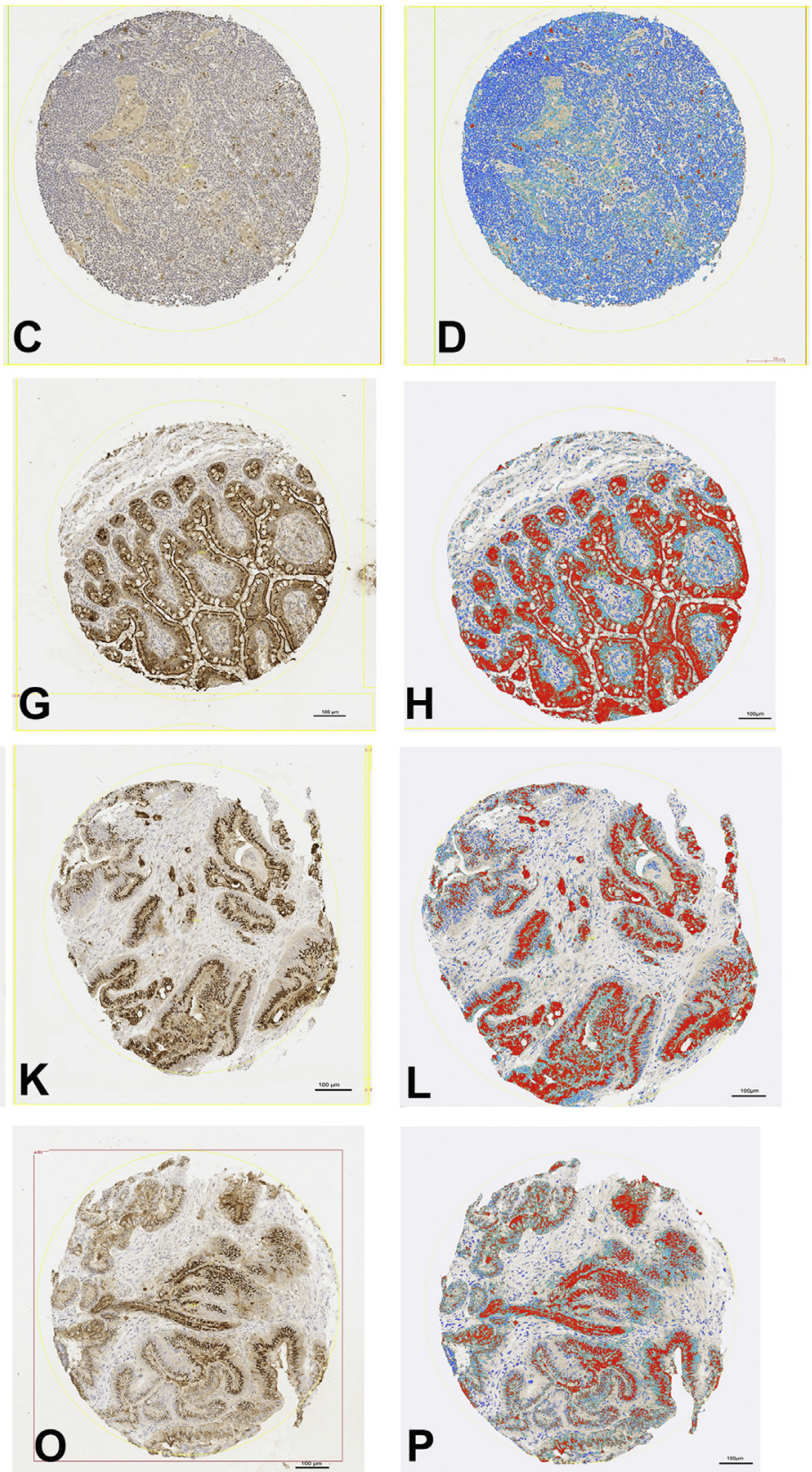

Fig. 1 An example of immunohistochemical expression of FOXP3 and IDO in colorectal cancer, expressed as area tissue percentage at different sites (for each site, an immunostaining image and the corresponding digital mark-up are presented). Tumour-draining lymph node without metastasis: (A,B) 5.8\% for FOXP3, and (C,D) $2 \%$ for IDO. Healthy mucosa: (E,F) $1.1 \%$ for FOXP3, and (G,H) 100\% of epithelial cells area for IDO. Tumour centre: (I,J) 10.3\% for FOXP3, and (K,L) 100\% of neoplastic cells for IDO. Tumour front: (M,N) $6.6 \%$ for FOXP3, and (O,P) 83\% of neoplastic cells for IDO. For digital mark-up, red corresponds to positive staining and blue negative. Scale bars $=100 \mu \mathrm{m}$. 
Table 2 Proportions of IDO+ and FOXP3+ tissue areas in central tumour $(\mathrm{C})$, invasive front of the tumour $(\mathrm{F})$, tumour-draining lymph node without metastasis (N-), tumour-draining lymph node with metastasis $(\mathrm{N}+)$, and normal mucosa $(\mathrm{M})$

\begin{tabular}{|c|c|c|c|c|c|}
\hline & $\mathrm{C}(n=31)$ & $\mathrm{F}(n=31)$ & $\mathrm{N}-(n=31)$ & $\mathrm{N}+(n=13)$ & $\mathrm{M}(n=31)$ \\
\hline $\mathrm{FOXP} 3+\operatorname{area}(\%)$ & $2.3 \pm 1.8$ & $2.6 \pm 2.9$ & $6.0 \pm 2.9^{\mathrm{a}}$ & $14.2 \pm 2.9^{\mathrm{b}}$ & $1.2 \pm 0.8$ \\
\hline IDO+ area in lamina propria $(\%)$ or in non-epithelial area of lymph node & $1.6 \pm 3.1$ & $1.1 \pm 1.3$ & $3.4 \pm 2.5^{\mathrm{a}}$ & $9.1 \pm 8.5^{\mathrm{b}}$ & $1.8 \pm 3.0$ \\
\hline IDO+ area in epithelial cells (\%) & $7.2 \pm 11.9$ & $7.2 \pm 13.9$ & N/A & $6.7 \pm 5.4$ & $5.4 \pm 13.8$ \\
\hline
\end{tabular}

Results are expressed as mean $\pm \mathrm{SD}$.

N/A, not applicable.

${ }^{\mathrm{a}} p<0.001 \mathrm{~N}-$ vs $\mathrm{C}, \mathrm{F}$ and $\%$.

${ }^{\mathrm{b}} p<0.001 \mathrm{~N}+$ vs $\mathrm{C}, \mathrm{F}, \mathrm{N}-$ and $\mathrm{M}$.

cells and normal epithelial cells. In the same section, staining of IDO occurred both in cancer cells and normal epithelial cells and in dendritic cells (lamina propria) (Fig. 1D,F,H).

\section{Comparison of the expression of IDO and FOXP3 among the different sites in CRC patients}

The proportion of tissue area positive for IDO was significantly higher in lymph node than in the lamina propria of normal mucosa, or in the stroma of carcinomatous samples $(p<0.0001)$ (Table 2). The proportion of tissue area positive for IDO was significantly higher in $\mathrm{N}+$ than in $\mathrm{N}-(p<0.01)$. There was no statistically significant difference in FOXP3 and IDO between the centre of the tumour and the invasive front.

\section{Comparison of the expression of IDO and FOXP3 in healthy mucosa between CRC patients and controls}

The proportion of IDO positive tissue area in the lamina propria was not significantly different between healthy mucosa of patients with cancer than without $(1.8 \pm 3$ vs $1.1 \pm 0.9)$. The proportion of IDO positive tissue area in the epithelium was significantly higher in healthy mucosa of patients with cancer than without $(5.4 \pm 13.8$ vs $2.1 \pm 2.4$, $p=0.001)$.

The proportion of FOXP3 positive tissue area was significantly higher in healthy mucosa of CRC patients than controls $(1.2 \pm 0.8$ vs $0.8 \pm 0.5, p=0.03)$.

\section{Association between the proportion of tissue area positive for IDO and FOXP3 in different sites (Table 3)}

FoxP3 in tumour was positively correlated with IDO in N$(\mathrm{r}=0.44, p<0.01)$ but not in $\mathrm{N}+$.

Table 3 Correlations of immunohistochemical expression of IDO and FOXP3 between different sites

\begin{tabular}{lll}
\hline & $\mathrm{r}$ & $p$ \\
\hline FOXP3 (F)/IDO (N+) & 0.1 & 0.7 \\
FOXP3 (F)/IDO (N-) & 0.44 & 0.005 \\
FOXP3 (N-)/IDO (F) & 0.26 & 0.16 \\
FOXP3 (N+)/IDO (F) & 0.35 & 0.11 \\
FOXP3 (M)/IDO (N+) & 0.19 & 0.63 \\
FOXP3 (M)/IDO (N-) & 0.41 & 0.05 \\
\hline
\end{tabular}

$\mathrm{F}$, invasive front of the tumour; $\mathrm{M}$, normal mucosa; $\mathrm{N}-$, tumour-draining lymph node without metastasis; $\mathrm{N}+$, tumour-draining lymph node with metastasis; $p$, value of statistical significance; $r$, coefficient of correlation of Spearman.

\section{Serum concentration of Kyn}

The concentration of Kyn was not significantly different in patients with CRC (1.68 \pm 0.59 , median 1.6, range 0.6-3.1) than in patients without $(1.57 \pm 0.79$, median 1.3 , range $0.8-2.9 ; p=0.07)$. The $\mathrm{Kyn} / \mathrm{Trp}$ ratio was not different in patients with CRC than in patients without $(0.05 \pm 0.02$ vs $0.04 \pm 0.01 ; p=0.05)$. The serum concentration of Kyn or the $\mathrm{Kyn} / \mathrm{Trp}$ ratio was not correlated with the proportion of tissue epithelial area positive for IDO in any sites of CRC patients. No difference in Kyn or Kyn/Trp ratio was found according to the TNM or VELIPI stages.

\section{DISCUSSION}

Our study, combining TMA and digital whole slide, gave a precise description of IDO and FOXP3 infiltration in different sites of colorectal tissue removed from patients operated on for CRC and healthy mucosa of patients without tumour. Studies of inflammatory cells in cancer have gained increasing interest, particularly with regard to tumour invasiveness. The composition of the microenvironment is of prognostic importance in $\mathrm{CRC},{ }^{9,16}$ and new drugs targeting the microenvironment are currently under development. ${ }^{17}$ Because the TMA method allows the simultaneous analysis of selected regions from histological materials assembled on a single microscopy slide, it is a time- and cost-saving method. This method has been validated when investigating markers expressed by tumour cells, ${ }^{18,19}$ as well as surrounding cells in the tumour stroma. ${ }^{14}$

Because some evidence exists that cells expressing IDO can suppress T-cell responses and promote tolerance, ${ }^{2,21}$ we were interested in the combined study of IDO+ and FOXP3 cells infiltration. For the morphometric analysis, we manually differentiated epithelial IDO+ cells from dendritic IDO+ cells. In non-metastatic draining tumour lymph node, since IDO+ cells are only dendritic cells, they could be detected automatically by morphometric analysis. Interestingly, the proportion of IDO+ area in the lamina propria was significantly higher in $\mathrm{N}+$ than in $\mathrm{N}-$, and significantly higher in $\mathrm{N}$ - than in other studied sites (Table 2). This suggests the importance of the presence of dendritic cells in lymph node, as much as the node is invaded by the cancer. We found that the proportion of IDO+ epithelial cells was higher in healthy mucosa of patients with CRC than in patients without. Such an observation has not been reported previously, because no case-control studies have compared pieces of surgical colectomy from patients with and without CRC. The same observation was made for FOXP3 infiltration, which was greater in healthy mucosa of CRC patients. Thus, healthy 
mucosa of patients with CRC seems to be the site of the inflammatory reaction.

Contrary to Brandacher et al., ${ }^{13}$ who found a correlation between IDO immunoreactivity of CRC cells and frequency of liver metastases, we did not find any relationship between IDO expression in neoplastic cells and TNM stage. Some explanations can be given for these discrepancies. Firstly, these authors considered only cancer cell lines from which IDO activity was analysed by reverse transcription-PCR. By contrast, in our immunohistochemical study, IDO was expressed by tumour and normal epithelial cells. Secondly, these authors could easily separate samples with high IDO expression from those with low expression using PCR method. In the present study, we could only confirm that infiltration by IDO+ cells is higher in healthy mucosa of CRC patients than in those without cancer and that IDO expression was not higher inside the tumour (with no difference between the centre and invasive front) than in healthy mucosa. Gao et $a .^{22}$ also reported the absence of difference in IDO expression between normal adjacent mucosa and primary tumour and suggested that it is unlikely that IDO contributes to tumour progression in primary CRC.

Concerning FOXP3, Salama et al. ${ }^{9}$ studied the density of tumour-infiltrating lymphocytes bearing FOXP3 (for Tregs) semi-quantitatively using whole slide digital images derived from TMA. They also confirmed a higher density of cells positive for FOXP3 in tumour compared with adjacent normal mucosa. They explored neither lymph node nor IDO infiltration.

The Trp degradation by IDO from CRC cells, activated macrophages, or dendritic cells, ${ }^{20}$ does result in an increase in the Kyn level in the tumour microenvironment and could induce tumour tolerance. ${ }^{21}$ Our results are different to those reported by Suzuki et al. $^{23}$ in lung cancer; they found that Kyn concentrations in the blood were significantly higher and Trp concentrations significantly lower in patients with cancer than in healthy controls. In addition, our study failed to show any increase in the Kyn/Trp ratio in more advanced stages. ${ }^{13,22,23}$ The extraordinary complexity of Trp and Kyn metabolism ${ }^{24}$ and their regulation in the whole body could be the cause of these discrepant results. The Kyn/Trp ratio in the tumour reflects IDO activity in the relatively closed system of the tumour, but perhaps not that in the blood. The lack of statistical power of our study could be another explanation for the discrepancy.

An interesting result of our study is the positive correlation between the infiltration of FOXP3+ cells in tumour and IDO+ cells in $\mathrm{N}-$ but not in $\mathrm{N}+$. Tregs develop in peripheral lymphoid tissues from naïve $\mathrm{T}$ cells at a very low frequency, and the local environment is the key to the generation of Tregs. $^{25}$ Tumour cells can directly initiate the induction of Tregs through several factors including IDO, IL-10, and TGF$\beta$, and modulate APCs, whether tissue-resident or recruited from lymph node to become tolerogenic, which thereby strongly contribute to the induction of Tregs (FOXP3+) within the tumour microenvironment, normal mucosa, or draining lymph nodes. ${ }^{25}$ Our results in CRC illustrated the classical theory of Treg recruitment to the lymph node draining the cancer after the interaction of APC with tumour antigens. In $\mathrm{N}+$, the great quantity of cancer cells prevents recruitment of APC, which could explain the lack of correlation.

This study showed that immunohistochemistry performed on TMA is a good technique for analysing the CRC environment. It is much simpler that immunostaining performed on whole tissue samples. ${ }^{4,9,26}$ Moreover, five cylinders of tissue were analysed for each site, allowing for minimal sampling error related to tissue heterogeneity. Computerised images of whole TMA glass slides permit standardisation of the analysis, which is impossible with the human eye. Contrary to the technique of gene expression profiling and flow cytometry in which the architecture of tissues is destroyed, immunohistochemical techniques applied to TMA allow analysis of the spatial relations between different cell types in lymph nodes for a large number of samples, which is a promising research method. ${ }^{2,27,28}$ Moreover, gene profiling and flow cytometry require living cells extracted from tumour and depend on the quality of extraction procedure and time of preservation. One limitation of our study is the small size of the sample, which could explain the large confidence interval observed for some of our results.

In conclusion, this study showed for the first time that the TMA technique permits simultaneous analysis of FOXP3+ and IDO+ cells at different anatomical sites, including tumour, draining non-metastatic and metastatic lymph nodes, and normal mucosa. The strong correlation between FOXP3+ areas and IDO+ area in $\mathrm{N}-$ but not in $\mathrm{N}+$, constitutes an argument in favour of interactions between Tregs and APCs within the tumour and the draining lymph nodes. This method, which allows for better analysis of the inflammatory infiltrate in different anatomical sites, both within and outside the tumour, should be used for larger studies.

Conflicts of interest and sources of funding: The authors state that there are no conflicts of interest to disclose.

Address for correspondence: Dr Daniel Eyraud, Service d'Anatomie Pathologique, Hôpital Pitié-Salpêtrière, 47-83 Boulevard de l'Hôpital, 75013 Paris, France. E-mail: daniel.eyraud@aphp.fr

\section{References}

1. Brenner H, Kloor M, Pox CP. Colorectal cancer. Lancet 2014; 383 1490-502.

2. Miller TJ, McCoy MJ, Hemmings C, et al. The prognostic value of cancer stem-like cell markers SOX2 and CD133 in stage III colon cancer is modified by expression of the immune-related markers FoxP3, PD-L1 and CD3. Pathology 2017; 49: 721-30.

3. Galon J, Costes A, Sanchez-Cabo F, et al. Type, density, and location of immune cells within human colorectal tumors predict clinical outcome. Science 2006; 313: 1960-4.

4. Laghi L, Bianchi P, Miranda E, et al. CD3+ cells at the invasive margin of deeply invading (pT3-T4) colorectal cancer and risk of post-surgical metastasis: a longitudinal study. Lancet Oncol 2009; 10: 877-84.

5. Chiba T, Ohtani H, Mizoi T, et al. Intraepithelial CD8+ T-cell-count becomes a prognostic factor after a longer follow-up period in human colorectal carcinoma: possible association with suppression of micrometastasis. Br J Cancer 2004; 91: 1711-7.

6. Menon AG, Janssen-van Rhijn CM, Morreau H, et al. Immune system and prognosis in colorectal cancer: a detailed immunohistochemical analysis. Lab Invest 2004: 84: 493-501.

7. Sobhani I, Le Gouvello S. Critical role for $\mathrm{CD}^{+} \mathrm{FoxP}^{+}$regulatory cells in colon cancer immune response in humans. Gut 2009; 58: 743-4

8. Chaput N, Louafi S, Bardier A, et al. Identification of CD $8^{+} \mathrm{CD} 25^{+} \mathrm{FoxP} 3+$ suppressive T cells in colorectal cancer tissue. Gut 2009; 58: 520-9.

9. Salama P, Phillips M, Grieu F, et al. Tumor-infiltrating FOXP3-T regulatory cells show strong prognostic significance in colorectal cancer. $J$ Clin Oncol 2008; 27: 186-92.

10. Vignali AA, Collison LW, Workman CJ. How regulatory T cells work Nat Rev Immunol 2008; 8: 523-32.

11. Poitrasson-Rivière $\mathrm{M}$, Bienvenu $\mathrm{B}$, Le Campion $\mathrm{A}$, Bocourt $\mathrm{C}$, Martin B, Lucas B. Regulatory CD4+ T cells are crucial for preventing CD8+ T cell-mediated autoimmunity. J Immunol 2008; 180: 7294-304.

12. Mellor AL, Munn DH. IDO expression by dendritic cells and tryptophan catabolism. Nat Rev Immunol 2004; 4: 762-74. 
13. Brandacher G, Perathoner A, Ladurner R, et al. Prognostic value of indoleamine-2,3-dioxygenase expression in colorectal cancer: effect on tumor-infiltrating T cells. Clin Cancer Res 2006; 12: 1144-51.

14. Glimelius I, Qvarnström F, Simonsson M, et al. Tissue microarray and digital image analysis: a methodological study with special reference to the microenvironment in Hodgkin lymphoma. Histopathology 2012; 61: 26-32.

15. Yamada K, Miyazaki T, Shibata T, Hara N, Tsuchiya M. Simultaneous measurement of tryptophan and related compounds by liquid chromatography/electrospray ionization tandem mass spectrometry. J Chromatogr B: Anal Technol Biomed Life Sci 2008; 867: 57-61.

16. Pagès F, Berger A, Camus $\mathrm{M}$, et al. Effector memory $\mathrm{T}$ cells, early metastasis and survival in colorectal cancer. $N$ Engl J Med 2005; 353 2654-66.

17. Hanna E, Quick J, Libutti SK. The tumour microenvironment: a novel target for cancer therapy. Oral Dis 2009; 15: 8-17.

18. Camp RL, Neumeister V, Rimm DL. A decade of tissue microarrays: progress in the discovery and validation of cancer biomarkers. $J$ Clin Oncol 2008; 26: 5630-7.

19. Hedvat CV, Hegde A, Chaganti RS, et al. Application of tissue microarray technology to the study of non-Hodgkin's and Hodgkin's lymphoma. Hum Pathol 2002; 33: 968-74.

20. Uyttenhove C, Pilotte L, Théate I, et al. Evidence for a tumoral immune resistance mechanism based on tryptophan degradation by indoleamine 2,3-dioxygenase. Nat Med 2003; 9: 1269-74.
21. Munn DH, Mellor AL. Indoleamine 2,3-dioygenase and tumor-induced tolerance. J Clin Invest 2007; 117: 1147-54.

22. Gao YF, Peng RQ, Li J, et al. The paradoxical patterns of expression of indoleamine 2,3-dioxygenase in colon cancer. J Translational Med 2009; 7: 71 .

23. Suzuki Y, Suda T, Furuhashi K, et al. Increased serum kynurenine/ tryptophan ratio correlates with disease progression in lung cancer. Lung Cancer 2012; 67: 361-5.

24. Kolodziej LR, Paleolog AM, Williams RO. Kynurenine metabolism in health and disease. Amino Acids 2011; 41: 1173-83.

25. Mougiakakos D, Choudhury AL, Kiessling R, Johanson C. Regulatory T cells in cancer. Adv Cancer Res 2010; 107: 57-117.

26. Sincrope FA, Rego RL, Ansell SM, Knutson KL, Foster NR, Sargent DJ. A low intraepithelial effector (CD3)/regulatory (FoxP3) T cell ratio predicts adverse outcome of human colon carcinoma. Gastroenterology 2009; 137: 1270-9.

27. Zlobec I, Baker K, Minoo P, Jass JR, Terracciano L, Lugli A. Nodenegative colorectal cancer at high risk of distant metastasis identifiec by combined analysis of lymph node status, vascular invasion, and Raf-1kinase inhibitor protein expression. Clin Cancer Res 2008; 14: $143-8$.

28. Matera L, Sandrucci S, Mussa A, Boffa C, Castellano I, Cassoni P. Low FOXP3 expression in negative sentinel lymph nodes is associated with node metastases in colorectal cancer. Gut 2010; 59: 419-20. 